\title{
Discussão Epistemológica da Produção Científica de Programas de Pós-graduação na Área da Saúde Reprodutiva
}

JOSÉ RENATO G. CASTRO -

EGBERTO R.TURATO •

Este artigo apresenta resultados preliminares de pesquisa, que entende que as conseqüências da complexa relação "produção" (pesquisa) / "divulgação" (ensino) / "utilização" (consumo) reproduzem o modelo de pensamento newtoniano-cartesiano dominante no contexto acadêmico. Objetiva-se identificar o nível de discussão epistemológica existente nas teses de programas de pós-graduação das universidades estaduais paulistas (até o momento, analisaram-se teses da UNICAMP), com eleição da produção em Ginecologia, Obstetrícia e Mastologia. A seleção foi feita a partir do critério cronológico (as mais atuais), optando-se pela aleatoriedade quanto ao tipo metodológico das pesquisas. Através da análise hermenêutica e do critério de saturação, investigaram-se quatro categorias hipoteticamente demarcadas - visão de "pessoa", "saúde", "ciência" e "ética". Constatou-se que os trabalhos apresentam reduzida ou inexistente preocupação com reflexões epistemológicas. Os aspectos metodológicos são estruturados mantendo, quase que exclusivamente, preocupações protocolares numa perspectiva disciplinar e racionalista, o que inviabiliza a concretização de dinâmicas acadêmicas valorizadoras do enfoque transdisciplinar.

Palavras-chave: epistemologia; ética; medicina reprodutiva; educação.

Recebido em: 21/08/2007.

Aprovado em: 06/11/2007. 


\section{Introdução}

O cientista "normal", a meu juízo, foi mal ensinado. Acredito, e muita gente acredita como eu, que todo o ensino de nível universitário (e se possível de nível inferior) devia consistir em educar e estimular o aluno a utilizar o pensamento crítico... (POPPER, 1979, p. 65).

A evolução do pensamento humano e, como decorrência dessa evolução, o olhar atento sobre as perspectivas críticas dinamizadas por alguns pensadores e cientistas têm imposto aos campos das ciências um processo lento e fragmentado de evolução das perspectivas práxicas nos diversos campos do conhecimento. Agregada a essa consideração, existem claras e crescentes constatações e denúncias apresentadas através de publicações científicas, a partir das quais se podem reconhecer as insuficiências no âmbito das produções na interface Educação-Saúde.

Os resultados "perversos" (DURAND, 1998) obtidos pela evolução tecnológica, a frágil fundamentação ética de grande parte das linhas e programas que produzem conhecimentos científicos, o nível insatisfatório de competência crítica e de consciência epistemológica dos docentes-pesquisadores-formadores têm sido apresentados como motivos de descontentamento no contexto acadêmico.

Uma vez que posturas preocupadas com a produção tecnológica interferem continuamente no contexto social, expressivos são os resultados negativos que afetam o meio ambiente, as comunidades e a saúde pessoal. Assim sendo, indica-se que tais resultados emergem da complexa relação entre produção (pesquisa), divulgação (ensino) e utilização (consumo) (D’AMBRÓSIO, 2001), em decorrência do sistema que assume e reproduz características dominantes do modelo de pensamento newtoniano-cartesiano.

Em função disso, é possível reconhecer verdades contidas em inúmeras críticas formuladas por vários pesquisadores e epistemólogos. Portanto, mostra-se relevante o contínuo exercício de análise crítica que possa fornecer subsídio capaz de auxiliar o redirecionamento dos (des)caminhos que se manifestam a partir de conhecimentos produzidos, em grande parte, no interior dos sistemas de pós-graduação.

Pensadores como Kuhn (1979), Popper (1979), Japiassu (1992), Morin (2000 a, b, c), Santos (2000) e Demo (2002) têm apresentado críticas à Ciência 
e assumem posicionamentos de profunda insatisfação no que se refere à maneira (forma dominante) e ao atual estágio de produção de novos conhecimentos.

Autores como Camargo Jr. (1990, 1993, 2005), Minayo (1991), Ayres, (1994), Nunes (1995, 2002), Tesser e Luz (2002), Chaves (2002), Turato (2003), Iribarry (2003), Teixeira (2004) e Luz (2005) fazem parte desse universo de pesquisadores críticos, os quais integram suas idéias às questões que circulam no âmbito da formação de profissionais que atuarão na docência, na pesquisa e em funções técnicas na área da Saúde/Medicina. Tais referências reforçam a relevância acadêmica sobre a necessária reflexão-ação na busca de dados que demonstrem mais claramente o atual estado da arte relativo aos trabalhos também - na área da Saúde Reprodutiva.

Logo, não se pode deixar de relacionar as insuficiências acadêmicas aos efeitos colaterais que afetam a questão da saúde em geral e da mulher em particular: na condição de objeto, ela pode ser pesquisada e tratada com fundamentações teóricas e protocolos práticos racionalistas controladores do modus faciendi nos meios universitários.

Evidentemente, este artigo não tem o escopo de emitir juízos de valor quanto à competência científica na elaboração metodológica da pesquisa de seus autores, nem tampouco insinuar que as pesquisas oriundas da área da Saúde Reprodutiva apresentam falhas. As discussões aqui articuladas fazem menção às tendências dominantes de um paradigma que se manifestam e ficam registradas na linguagem das teses. Tal investigação poderia ser elaborada em programas de pós-graduação de naturezas diversas.

Partindo dessas considerações iniciais, apresentam-se os primeiros resultados do trabalho de pesquisa que vem realizando análise hermenêutica (RICOEUR, 1990; AYRES, 1994; ABIB, 1996; GADAMER, 1997; ABBAGNANO, 2000; GHEDIN, 2004) sobre o nível de discussão epistemológica existente em teses produzidas em programas de pós-graduação na área da Saúde Reprodutiva.

No entanto, para que se possa atingir um bom nível de clareza, e levando em conta a diversidade de elementos teóricos que foram emergindo no processo de revisão das referências, é necessário iniciar por um embasamento de pressupostos que abordam questões relativas ao desenvolvimento do pensamento científico, partindo das noções sobre paradigma tradicional para se chegar às de paradigma emergente (LAKATOS; MUSGRAVE, 1979; MASTERMAN, 
1979; HÜBNER, 1986; MORAES, 1997, 2001; SANTOS, 2000; MORIN, 2000b). Em seguida, lança-se um olhar sobre os conceitos que vêm sendo encontrados nas retóricas e publicações que procuram dar subsídios às dimensões práxicas "multidisciplinar", "interdisciplinar" e "transdisciplinar" (MORIN, 2000b, s/d; ASSMANN, 2001; D'AMBRÓSIO, 2001; FAZENDA, 2001; CAPRA, 2002; TURATO, 2003). E atenta-se também para a necessidade de reconhecer fundamentações epistemológicas (JAPIASSU, 1992; ABIB, 1996) sobre o "pensamento complexo" (MORIN, 1995, 2000b, 2000c).

A parte principal vem a seguir. Nela são apresentadas as etapas centrais da pesquisa, nas quais se explicitam as hipóteses, os objetivos, as etapas do método, os resultados preliminares e a discussão.

\section{Revisão de elementos teórico-epistemológicos}

Sabendo a que os cientistas dão valor, podemos esperar compreender os problemas pelos quais se responsabilizarão e as escolhas que farão em determinadas circunstâncias de conflito. (KUHN, 1979, p. 29).

A análise hermenêutica e a crítica epistemológica, que serão apresentadas nas partes finais deste texto, são feitas a partir de quatro categorias - visão de pessoa, visão de saúde, visão de ciência, visão de ética. Em função disso, e para que se chegue à compreensão das bases teóricas a partir das quais foram articuladas as discussões, há que se apresentar os pressupostos indicadores das tendências, e/ou cosmovisões, as quais podem emergir das teses que vêm sendo pesquisadas.

Partindo das características diferenciadoras entre os paradigmas (tradicional e emergente) e as tendências científicas e pedagógicas (multidisciplinar, interdisciplinar e transdisciplinar) é que serão demonstradas as visões dominantes, bem como a tendência de cada trabalho - daí a proposição dos subitens a seguir.

Os rumos do pensamento científico: do paradigma tradicional ao paradigma emergente

A esperança funda-se em possibilidades humanas inexploradas e aposta no improvável. Não é mais esperança apocalíptica na luta final. É esperança 
corajosa na luta inicial. Ela deve restaurar uma concepção, uma visão de mundo, um saber articulado, uma ética. Ela deve inspirar não apenas um projeto, mas uma resistência preliminar contra as forças gigantescas da barbárie que se desencadeia. Os que aceitarem o desafio virão de diversos horizontes, e pouco importa sob que etiqueta se reunirão (MORIN, 1993, p. 34).

Pode-se considerar que duas principais linhas de pensamento apresentamse como eixos para os debates sobre as perspectivas epistemológicas em nível mundial: uma denominada paradigma tradicional, ou positivista, ou newtonianocartesiano; outra, paradigma emergente, ou da complexidade, ou sistêmicoecológico (compreendendo algumas pequenas diferenças contidas nas expressões aqui utilizadas, em razão de seus respectivos proponentes e defensores).

Analistas apresentam o paradigma tradicional calcado no modelo da racionalidade, pensamento que se tem mantido desde a evolução científica no século XVI-XVII e a partir do qual se edificam as ciências naturais e, decorrente desse pensamento, as ciências sociais que emergem no século XIX.

Morin (2000b, p. 137-139) indica algumas das características que remontam esse arco histórico:

- um rigor disciplinar que postula a objetividade e a eliminação do sujeito;

- a matematização, a hiperformalização e a hiperabstração, as quais promovem o enclausuramento disciplinar;

- a redução da realidade mais complexa à menos complexa;

- a tendência de reaproximar os campos do conhecimento (ex.: Física, Biologia, Antropossociologia) realizando uma redução do biológico ao físico-químico, do antropológico ao biológico.

Também Santos (2000, p. 70-71) apresenta características do paradigma dominante, porém as articula com o que emerge dos novos pressupostos teóricos do paradigma da complexidade, indicando o que passa a ser valorizado nessa nova cosmovisão:

- no lugar da "eternidade", reconhece-se hoje a "história";

• em vez do "determinismo", a "imprevisibilidade"; 
- em vez do "mecanicismo", a "interpenetração", a "espontaneidade" e a "auto-organização";

• em vez da "reversibilidade", a "irreversibilidade" e a "evolução";

- em vez da "ordem”, a "desordem";

- em vez da "necessidade", a "criatividade" e o "acidente".

Pensar o movimento histórico e os caminhos da ciência e desvelar perspectivas epistemológicas sobre qual paradigma subsidia a dimensão práxica do fazer acadêmico, em função dessas diferenças e divergências, torna-se imprescindível, pois o que vem sendo operado na atual sociedade, toda ela já reestruturada por inúmeras ocorrências, descobertas e ações dos produtos da ciência que nela interfere, sinaliza que "o paradigma a emergir dela não pode ser apenas um paradigma científico (o paradigma de um conhecimento prudente), tem de ser também um paradigma social (o paradigma de uma vida decente)" (SANTOS, 2000, p. 74).

As noções de paradigma comportam várias vertentes, e Santos (2000, p. 74) traz uma lista de pensadores contemporâneos que nomeiam suas concepções de paradigma no atual estágio de evolução do pensamento científico, cada uma com sua expressão peculiar:

- Ilya Prigogine - "nova aliança e metamorfose da ciência";

- Fritjof Capra - "nova física e/ou taoísmo da física";

- Eugene Wigner - "mudanças do segundo tipo";

- Erich Jantsch - "paradigma da auto-organização".

Como parte final da revisão de autores que fornecem subsídios para que se possa continuar a tarefa de refletir sobre questões epistemológicas relativas aos paradigmas na ciência, retomam-se posições de Edgar Morin, ativo pensador francês que tem apresentado concepções abrangentes acerca de temas como a complexidade e a transdisciplinaridade.

Esse teórico nos apresenta uma obra de grande erudição e atualidade. Suas concepções e seus pronunciamentos (proferidos aberta e criticamente) procuram indicar suas discordâncias em relação ao que pensam outros teóricos contemporâneos. 
Como exemplo, temos a contraposição de Morin aos posicionamentos teóricos elaborados e propostos por Kuhn, Popper e Feyerabend (1965 apud LAKATOS; MUSGRAVE, 1979) e por outros autores que também buscaram dar explicações, sentidos e conceituações sobre a expressão/construto "paradigma":

Dei uma definição que aparentemente se situa como intermediária de definição da lingüística estrutural e da definição vulgata à maneira de Kuhn. Um paradigma é um tipo de relação lógica (inclusão, conjunção, disjunção, exclusão) entre um certo número de noções ou categorias-mestras. Um paradigma privilegia certas relações lógicas em detrimento de outras, e é por isso que um paradigma controla a lógica do discurso. O paradigma é uma maneira de controlar simultaneamente o lógico e o semântico.

Uma palavra também sobre a questão da ideologia. Para mim, a palavra ideologia tem um sentido totalmente neutro: uma ideologia é um sistema de idéias. Quando falo de ideologia, não denuncio nem designo as idéias dos outros. Reduzo uma teoria, uma doutrina, uma filosofia ao seu grau zero, que é ser um sistema de idéias (MORIN, 1995, p. 162).

Partindo dessas noções e sentidos sobre paradigma, destaca-se que a relação lógica que se mantém dominante e dominadora, ainda hoje, trabalha de forma dialética, porém numa perspectiva que sempre hipertrofiou a exclusão e restringiu demasiadamente o número de categorias-mestras necessárias para interpretar e lidar com a complexidade inerente ao fenômeno-objeto de investigação.

Para esta pesquisa, o objeto-humano não pode continuar sendo disciplinarizado, fragmentado, dissecado, excluído. Também não se pode manter a exclusiva maneira reducionista adotada pelo caminho da hiperespecialização; há que se trabalhar com um número crescente de categorias-mestras.

Acadêmica, administrativa, política e economicamente, constatam-se estratégias que se ocupam do controle da lógica do discurso, o qual tem procurado suprimir questões étnicas, semânticas, ideológicas, mercantis e éticas, fazendo com que o positivismo se mantenha de maneira hegemônica. Conseqüentemente, parece que o sistema acadêmico de produção vai, cada vez mais, validando a ditadura mecanicista-tecnicista, a qual parece ser inteligentemente autônoma e capaz de continuar produzindo disputas entre os campos disciplinares e entre seus operários.

Durante tais disputas, e contando com posturas autoprotetoras e consenso entre os pares (talvez em função da luta pela sobrevivência de suas 
"verdades" e por causa de níveis pouco suportáveis de sensações de insegurança e medo; situação compreensiva se utilizarmos referenciais psicanalíticos - medos básicos - o medo do ataque e o medo de perda do lugar seguro (PICHONRIVIÈRE, 1986, 1998), muitos pesquisadores-docentes devem experienciar um certo conforto-seguro: o de que "dominam o campo". Assim sendo, o necessário processo de revisão crítico-epistemológica desse sistema fica afastado, e muitos profissionais ampliam o coro, confirmando: "Isso é coisa de filósofo!" e/ou "Isso é muita teoria, na prática é outra coisa!".

Crendo que filosofar é exercício obrigatório para todos nós, indica-se um aprofundamento em elementos teóricos que passem a subsidiar melhor as diferenças existentes entre as abordagens multi, inter e transdisciplinar. Explicitados abaixo, complementa-se a revisão de pressupostos para a discussão final deste artigo.

\title{
Pesquisa, ensino e enfoques multidisciplinar, interdisciplinar e transdisciplinar
}

\begin{abstract}
A fundamentação teórica que serve de base à transdisciplinaridade repousa sobre o exame, na íntegra, do processo de geração, organização intelectual, organização social e difusão do conhecimento. Esse exame depende de uma crítica que emerge, inevitavelmente, da nossa tradição disciplinar. Nesse contexto, poder-se-ia dizer que o projeto transdisciplinar é intra e interdisciplinar, abarcando o que constitui o domínio das ciências da cognição, da epistemologia, da história, da sociologia, da transmissão do conhecimento e da educação (D’AMBRÓSIO, 2001, p. 15).
\end{abstract}

Um trabalho que se propõe a valorizar o aumento das competências teóricas não poderia furtar-se ao aprofundamento de investigações - as quais vão tomando consistência através da revisão dos pressupostos aqui articulados - que destaquem a inter-relação e a interdependência entre produção do conhecimento, divulgação através do ensino e conseqüente utilização dos resultados por parte dos profissionais-técnicos (graduandos, graduados e pós-graduados) nas diversas instituições que formam e/ou que se ocupam de cuidar de pessoas.

Tomando por base essa intrincada relação, destaca-se a simultânea importância de que os cuidadores-profissionais sejam capazes de aprender a 
cuidar de si mesmos e de manter boas condições para um processo de autoconhecimento. Nessa linha de preocupação, apresenta-se a questão proposta por Turato (2003, p. 532): como se pode preparar profissionais "para trabalhar com sofrimentos e as doenças das pessoas e das comunidades, estabelecer condutas terapêuticas amplas e ter grande probabilidade de eficácia, se esses profissionais não têm visão do locus que ocupam no contexto sócio-histórico e dos paradigmas que sustentam suas ações?"

D’Ambrósio (2001, p. 76) também indica problemas que afetam a visão de mundo dos docentes-pesquisadores e a maneira com a qual se vem produzindo o conhecimento. Ele chama a atenção para fatores que se manifestam a partir das limitações circunscritas às personalidades envolvidas, por vezes com posições pouco maduras, as quais corroboram "um cenário de competitividade, contradições e controvérsias, onde afloram componentes emocionais e morais". Portanto, a assunção de determinados tipos de enfoques científicos e pedagógicos, os quais variam em níveis herméticos e disciplinares em franca oposição aos posicionamentos validadores de uma abertura transdisciplinar, vão sendo assumidos e reproduzidos, tornando-se parte natural da construção permanente de uma noção de realidade.

Assmann (2001) apresenta um glossário por meio do qual se confere que as expressões multi/pluri, inter, trans têm em comum o fato de serem um "enfoque pedagógico e científico". Para além disso, o autor estabelece uma hierarquia entre esses três tipos de enfoque, validado pelas posições indicadas por Japiassu (1976), Jantsch (1995), Nunes (1995, 2002), Abib (1996), Gadotti (2000). A partir dessa constatação, deduzem-se possibilidades de direcionamento das intenções da interface educação-pesquisa, alvo de toda a preocupação deste trabalho.

Para Assmann (2001), a multidisciplinaridade e a pluridisciplinaridade se caracterizam como enfoques que são aplicados a atividades e projetos pedagógicos e científicos dos quais vários especialistas, com seus respectivos conhecimentos, participam, permanecendo cada qual com a visão mais ou menos restrita à sua área.

Com relação ao enfoque interdisciplinar, fica clara a tentativa explícita de se ir além da mera justaposição das contribuições de várias disciplinas. A interdisciplinaridade se empenha em estabelecer um intercâmbio enriquecedor entre profissionais e especialistas de diversas áreas do conhecimento científico. 
Além disso, o posicionamento interdisciplinar reconhece a insuficiência de contribuições que se mantêm restritas à dimensão e aos fazeres disciplinares.

Difícil de se edificar, porém anunciada, de muito, em discursos de importantes teóricos, como é o caso de Gadotti (2000, p. 225), a transdisciplinaridade é considerada pelas ciências da Educação "como a coordenação de todas as disciplinas e interdisciplinas do sistema de ensino inovado sobre a base de uma axiomática geral, ética, política e antropológica".

Face às formas dissimuladas com as quais os poderes vão semeando “crescente iniqüidade entre indivíduos, comunidades, nações", D’ Ambrósio (2001, p. 80) registra que a transdisciplinaridade não é uma nova filosofia, e/ou uma nova metafísica, tampouco pretende ser uma ciência das ciências. Indica que, por meio de posturas humildes e cooperativas, se passe a respeitar as diversas possibilidades de construção de conhecimento sem a necessidade de se excluir e desvalorizar mitos, religiões e sistemas diversos de explicações. Portanto, o projeto transdisciplinar rejeita qualquer tipo de arrogância e prepotência.

Das afirmações de Assmann (2001), destaca-se o caráter radical do questionamento epistemológico, o qual só é capaz de se edificar através do devir consciente, crítico, transformador que ocorre na e através da transdisciplinaridade.

\section{Aspectos metodológicos}

Faz-se necessário explicitar, inicialmente, o reconhecimento de conflitos, contradições e outros tipos de abordagens que transitam entre os pólos demarcados por esta pesquisa. Mas é fundamental registrar que a opção metodológica por tais pólos se funda, conforme se constatou através da revisão de literatura, em epistemólogos de renome, os quais denunciam continuamente a existência de um mal-estar que se perpetua em decorrência da manutenção de certezas sustentadas de maneira ilusória e ideológica através da herança positivista representada pelo paradigma tradicional.

Por outro lado, diante do panorama atual relativo a propostas mais integradoras, o pensamento complexo e o enfoque transdisciplinar em ensino e pesquisa apresentam-se como perspectivas que reconhecem os avanços materiais oriundos do paradigma tradicional (desenvolvimento não- 
desqualificável), que respeitam e valorizam outras dimensões, tradições e dinâmicas da experiência humana responsáveis pela construção do conhecimento e edificadas na relação homem-homem, homem-espiritualidade, homem-ciência, homem-política, homem-natureza, homem-produção. Sendo assim, interessa a este trabalho a dinamização de um olhar investigativo sobre elementos teóricos que indiquem quais os níveis de integração ou desintegração das características propostas pelo que hoje se nomeia de paradigma emergente.

Após tais justificativas, hipoteticamente, indica-se que (a) a produção acadêmica em cursos de pós-graduação stricto sensu, na área da Saúde Reprodutiva, apresenta níveis insuficientes de discussão epistemológica relacionada às visões de pessoa, saúde, ciência, ética.

Decorrente disso, (b) os processos de produção de novos conhecimentos (pesquisa) e de divulgação (ensino) mantêm a tradição disciplinar e não apresentam elementos teórico-metodológicos suficientes que indiquem condições favoráveis para se trabalhar, com clareza, sob o enfoque transdisciplinar.

Objetiva-se com isso:

- verificar a existência, ou a inexistência, de discussões sobre questões teórico-epistemológicas, bem como seu nível de aprofundamento em teses elaboradas por programas de pós-graduação das universidades estaduais paulistas, com eleição da produção em Ginecologia, Obstetrícia e Mastologia (Saúde Reprodutiva);

- verificar se os padrões de organização teórico-metodológicos favorecem discussões adequadas a pressupostos que reforçam a lógica do enfoque disciplinar, em detrimento do enfoque transdisciplinar;

- identificar elementos epistemológicos relativos às visões de pessoa, saúde, ciência e ética, os quais deverão emergir durante o processo de análise hermenêutica.

\section{Método}

A amostra final da pesquisa inclui teses dos programas de pós-graduação stricto sensu da UNESP-Botucatu, da UNICAMP-Campinas e da USPRibeirão Preto. Para a apresentação deste artigo, foram analisados os últimos 
cinco trabalhos apresentados até o mês de novembro de 2004, no programa de Tocoginecologia da Faculdade de Ciências Médicas da UNICAMP.

É intencional a não-revelação dos nomes dos autores e de seus respectivos orientadores, bem como dos títulos completos dessas teses. Indicase apenas que tais teses tratam dos seguintes temas: T1 - Comparação entre a técnica tradicional de fertilização in vitro (FIV) e a técnica de injeção intracitoplasmática (ICSI); T2 - Reconstrução mamária após mastectomia por câncer; T3 - Comparação entre utilização de dois tipos diferentes de gel para tratamento da vaginose bacteriana; T4 - Infecção genital por HPV e anormalidades na citologia cervical; T5 - Associação entre mutações genéticas e trissomia cromossômica.

A inclusão dos trabalhos se dá a partir do critério cronológico (as mais atuais), e se considera o critério de saturação dos elementos coletados nas categorias de análise como quesito para a delimitação final da amostra. Quanto ao tipo metodológico dessas pesquisas, optou-se pela aleatoriedade, pois se entende que tanto uma pesquisa quantitativa quanto uma pesquisa qualitativa podem apresentar posicionamentos reducionistas; e também que a objetividade ou a subjetividade podem ser trabalhadas de maneira mais ampla em qualquer tipo de protocolo de pesquisa.

Ao se iniciar o processo de análise dos textos (análise hermenêutica), a preocupação fica direcionada para questões epistemológicas amplas, relacionadas às diferentes cosmovisões, compreendendo que pessoa, saúde, ciência e ética são componentes de um mesmo fenômeno e emergem sistemicamente de um conjunto único de processo fenomênico. No entanto, há a necessidade didática de se organizar os dados coletados em categorias independentes. Na verdade, o que se busca é uma grande reflexão (a posteriori), a qual estará preocupada com questões fundamentais de bioética (LUNA; SALLES, 2000; CADAVID, 2001; OSUNA, 2003), ao mesmo tempo em que se vai acreditando que o papel dos professores-pesquisadores é utilizar a epistemologia como ferramenta para "desmascarar a ilusão dos que pretendem conferir 'à ciência' uma importância global que suprime a filosofia” (JAPIASSU, 1992, p. 92).

O processo de análise hermenêutica (leitura interpretativa) é feito através de repetidas revisões de todo o material selecionado, com atenção a quatro categorias. A partir do texto analisado, será possível captar se a "visão de pessoa" confere ao ser humano características de um sujeito dotado de uma complexidade que precisa ser considerada, ou se serve como um dos elementos- 
objeto de pesquisa, de modo que suas dimensões subjetivas, suas condições históricas, sociais e culturais não sejam contempladas. Logo, será possível reconhecer a dicotomia entre pessoa-sujeito e pessoa-objeto que está, implícita ou explicitamente, registrada.

O mesmo procedimento se aplica à investigação da "visão de saúde" (reprodutora da assunção de concepções biologicista-tecnicista-intervencionistas ou biopsicossocial-integradora-preventivas) e da "visão de ciência" (validadora do paradigma tradicional, o qual lida exclusivamente com a objetividade, ou transformadora através dos pressupostos do paradigma emergente, que reconhece a complexidade dos fenômenos, o limite do método científico e assume a necessidade de procedimentos metodológicos mais abrangentes).

Como categoria fundamental a ser pesquisada - e que subjaz a união dos elementos analisados através das outras categorias -, considera-se a possibilidade de identificar e/ou diferenciar as "visões de ética" (polarizadas entre o comprometimento com interesses mercantis ou claramente atentas à manutenção de toda forma de vida).

Duas possibilidades parecem se adequar aos pressupostos que alicerçam e validam as visões de mundo representadas pelo paradigma tradicional e pelo paradigma emergente. A primeira traz em seu bojo uma visão materialista e determinista do fenômeno humano, e interesses político-partidários e mercantilistas podem ser favorecidos, mesmo que os pesquisadores não possam alcançar (através de um razoável nível de consciência crítica) tal possibilidade. A segunda reconhece a vida como valor supremo, vida que ocorrerá de forma saudável num ambiente preservado; portanto, não desconsidera a necessária união entre ecologia interior e ecologia planetária.

A partir do reconhecimento da adequação do conceito de transdisciplinaridade como um enfoque que "transcende a dinâmica da simples síntese dialética e que almeja a apreensão da dinâmica da realidade enquanto totalidade" (JANTSCH, 1995, p. 31), e considerando que a reflexão epistemológica vem depois da Ciência, da História, da Psicologia, da Sociologia (ABIB, 1996), os procedimentos para a concretização do processo sistêmico-interpretativo de discussão dos dados procuram integrar a análise objetiva do texto escrito às críticas elaboradas pelos vários pensadores e epistemólogos (apresentados nos subitens 2.1 e 2.2). Portanto, o método de análise busca identificar as características antagônicas que determinam concepções e cosmovisões. 
Finalizando, destacam-se, das orientações de Abib (1996, p. 222), os principais pressupostos que qualificam elementos e norteiam processos de análise crítico-epistemológica:

- o objeto da epistemologia: "o texto";

- o motivo e o objetivo da investigação: "a pluralidade e o esclarecimento do texto";

- a tarefa do método: "interrogar o texto através de categorias que lidam com a possibilidade, os fundamentos (origens ou limites) e a verdade do conhecimento";

- a busca da validação da interpretação crítica: "investigar a correspondência e o consenso da utilidade prática da verdade, a coerência interna das idéias e da linguagem".

É da sua situação ou de seu contexto, bem como é de sua pré-compreensão ou de seu pré-texto que o intérprete interpela o texto. De um lado, visa a esclarecer o sentido do texto ou interpretar seu sentido; de outro, pretende revelar um mundo possível ou interpretar seu significado. Essa tensão que atravessa a reflexão hermenêutica alcança, portanto, a vertente hermenêutica do método epistemológico. E ela pode ser essencial para o método, porque não somente é possível que em função da relação entre a situação do texto e a situação do intérprete os significados atribuídos ao texto não sejam totalmente delirantes ou fantasiosos, mas também porque a situação do intérprete pode ser a pedra de toque para revelar um projeto de mundo do texto. É essa tensão essencial que pode ser condição de possibilidade para revelar um mundo possível, que não é somente o mundo do autor ou do intérprete, mas um mundo que ultrapassa e sintetiza situações, que é obra do intérprete e que, ao realizá-la, constitui-se como sujeito (ABIB, 1996, p. 226-7).

\section{Resultados preliminares e discussão}

É vício acadêmico aceitar como conhecimento adequado a mera absorção teórica, contornada cá e lá de alguns estágios. A própria extensão universitária corresponde, em última análise, à má consciência de uma instituição que sabe 
estar no mundo da lua e precisa demonstrar em algum lugar que toca o chão. Isto mostra quão distante está a universidade do compromisso de inovar pela via do conhecimento construído (DEMO, 2002, p. 28).

Os resultados encontrados vão permitindo confirmar as hipóteses da pesquisa, e identificamos que, na categoria "Visão de Pessoa", a noção de sujeito permanece ausente na maior parte dos textos. Como exemplo, destacamos dois trechos que demonstram a redução do fenômeno humano à visão limitada que impera na ilusão da objetividade científica: a) "podemos capacitar o espermatozóide"; b) "fator masculino de infertilidade é um termo utilizado para descrever casais".

Em "Visão de Saúde", a expressão "terapêutico(a)" está continuamente vinculada à inclusão de técnicas intervencionistas, através da utilização de equipamentos avançados e com tecnologia de ponta e/ou administração de novas drogas, em detrimento de abordagens multiprofissionais. Para exemplificar, destacamos o trecho: "Na tentativa de melhorar as possibilidades terapêuticas, várias outras técnicas foram surgindo."

A visão de saúde não aparece vinculada ao cuidado humano; está, em quase a totalidade dos textos analisados, relacionada à idéia de progresso científico-tecnológico, o qual se apresenta com excessiva preocupação pelo mensurável. Chama atenção o fato de que, mesmo diante da consciência de resultados contraditórios em relação às novas vidas que são manipuladas in vitro, a aplicação das técnicas não cessa, tampouco se identifica no texto o exercício crítico face aos resultados dos conhecimentos ali construídos. Como exemplo, destacam-se os seguintes trechos; a) "Publicações recentes mostraram que aneuploidia no cromossoma sexual e anomalias autossômicas estruturais estão significativamente aumentadas em crianças nascidas pós-ICSI"; b) "existem relatos sobre o potencial de anomalias durante a fertilização e também no bebê, como resultado desta técnica".

Em "Visão de Ciência", os aspectos metodológicos são estruturados mantendo, quase que exclusivamente, preocupações protocolares com perspectivas racionalistas e quantitativas. É acentuada a preocupação com aspectos econômico-mercantilistas, o que não é percebido como elemento desencadeador para autocrítica nesses trabalhos, que, embora racionais, em vários pontos se mostram pouco razoáveis, considerando-se as bases epistemológicas propostas pelo paradigma emergente. 
Em "Visão de Ética", a referência objetiva à Declaração de Helsinki III parece servir como um "sedativo para dores morais": pontos de impasse discutidos por outros documentos internacionais que se preocupam com a vida e a Bioética não foram registrados.

As concepções de ética estão estritamente vinculadas ao subitem apresentado em todos os sumários, "Aspectos Éticos", que se encontra bem destacado nas teses estruturadas pelo programa a partir do qual foi selecionada a amostra. Tal constatação demonstra a necessidade de se observar que o simples registro de que a) "houve informação prévia dos participantes"; b) "a pesquisa foi aprovada pelo comitê de ética"; c) "para a realização da pesquisa foram observados os princípios da Declaração de Helsinki III" não confere uma condição de competência crítica sobre os fenômenos investigados e sobre questões intrínsecas às próprias investigações propostas. Como exemplo, destacamos a pesquisa sobre a utilização de diferentes técnicas de fertilização; independentemente da técnica adotada, continua sendo um procedimento que envolve grandes problemas que reverberam no universo da Bioética: o que fazer com os embriões excedentes? A quem (sujeitos, equipes técnicas, laboratórios e clínicas-empresas, universidades, sistemas de saúde) caberia a responsabilidade de um processo continuado de apoio psicoterápico para o casal? Os casais que procuram a FIV/ICSI têm maturidade suficiente para suportar todos os possíveis problemas - principalmente nos casos de fracassos repetidos? Os atuais protocolos de aconselhamento genético são suficientes e eficazes?

Até o momento, apenas um dos trabalhos (que tem como tema a reconstrução mamária após mastectomia por câncer) demonstrou explicitamente uma visão humanista, atenta à noção de sujeito, aos atributos da feminilidade e à minimização dos problemas psicológicos. Essa tese toca constante e intencionalmente em importantes considerações, como: a) "inúmeras seqüelas físicas e emocionais que podem interferir na evolução da doença"; b) "O diagnóstico do tumor, o procedimento cirúrgico e os tratamentos sucessivos têm um impacto notável na qualidade de vida dessas mulheres"; c) "minimização do esquema corporal, pode suscitar problemas psicológicos no período seguinte à cirurgia, que se configuram principalmente em distúrbios ansioso-depressivos"; d) "Na sociedade moderna, a mama representa bem mais que um órgão associado à reprodução. Trata-se de um atributo da feminilidade e exerce importante papel no exercício da sexualidade". 
Ficam destacados os trechos acima como um alento e registro de um trabalho que, embora tivesse como objetivo comprovar a eficácia da técnica de reconstrução mamária, em momento algum perdeu de vista o cuidado com o ser humano que adoece, além de ter articulado discussões equilibradas, incluindo olhares para as dimensões psicológica, antropológica e sociológica. Logo, elabora reflexões interdisciplinares.

Até o momento, podemos concluir que o processo de análise hermenêutica vem permitindo bons níveis de sucesso para a formulação da crítica epistemológica, a qual se mostra fundamental para o aprimoramento dos métodos de ensino/ pesquisa e a consecução de melhores condições de trabalho acadêmico que busquem maior competência compreensiva diante dos fenômenos humanos.

Constatamos que, na categoria visão de pessoa, a noção de sujeito fica à margem na maior parte dos textos e que os trabalhos têm preocupação específica com o objeto de pesquisa. A visão de saúde está continuamente vinculada à valorização da inclusão de técnicas intervencionistas. A visão de ciência assume e reproduz protocolos com características racionalistas, tecnicistas, biologicistas, as quais denunciam a manutenção da lógica do paradigma tradicional. A visão de ética mantém estreito vínculo com as características de um modelo de ética materialista.

Assim sendo, vamos obtendo confirmação de que os trabalhos apresentam reduzida ou inexistente preocupação com reflexões epistemológicas. A visão disciplinar restringe a aproximação de algumas argumentações oriundas de outros campos do conhecimento (ex.: Antropologia, Sociologia, Psicologia, Psicanálise), submetendo o "biológico ao físico-químico, o antropológico ao biológico". Portanto, os exercícios argumentativos não demonstram características suficientes que indiquem as competências favoráveis ao enfoque transdisciplinar, por parte do universo acadêmico investigado.

Destacamos o caráter inicial da pesquisa e o necessário aprofundamento dos trabalhos de coleta de dados no restante da amostra.

\section{Referências}

ABBAGNANO, N. Dicionário de filosofia. São Paulo: Martins Fontes, 2000. ABIB, J. A. D. Epistemologia, transdisciplinaridade e método. Psicologia: teoria e pesquisa, v. 12, n. 3, p. 219-229, set./dez., 1996. 
ASSMANN, H. Reencantar a educação: rumo à sociedade aprendente. Petrópolis: Vozes, 2001.

AYRES, J. R. C. M. Interpretação histórica e transformação científica: a tarefa hermenêutica de uma teoria crítica da epidemiologia. Revista de Saúde Pública, v. 28, n. 4, p. 311-319, 1994.

CADAVID, J. C. B. Bioética y posmodernidad. Colômbia: Universidade de Manizales, 2001.

CAMARGO JR., K. R. A Biomedicina. Physis: Rev. de Saúde Coletiva, v. 15, n. esp. p. 177-201, 2005.

- A construção da AIDS: racionalidade médica e estruturação das doenças. 1993. Tese (Doutorado)-Programa de Pós-Graduação em Saúde Coletiva, Instituto de Medicina Social, Universidade do Estado do Rio de Janeiro, Rio de Janeiro, 1993.

. (Ir)Racionalidade médica: os paradoxos da clínica. 1990. Dissertação (Mestrado)- Programa de Pós-Graduação em Saúde Coletiva, Instituto de Medicina Social, Universidade do Estado do Rio de Janeiro, Rio de Janeiro, 1990.

CAPRA, F. As conexões ocultas: ciência para uma vida sustentável. São Paulo: Cultrix, 2002.

CHAVES, M. M. Complexidade e transdisciplinaridade: uma abordagem multidimensional do setor saúde. Disponível em: 〈http://www.nc.ufrj.br/ftp/ complexi.doc/>. Acesso em 26 out. 2002.

D’AMBRÓSIO, U. Transdisciplinaridade. São Paulo: Palas Athena, 2001.

DEMO, P. Pesquisa e construção do conhecimento: metodologia da pesquisa no caminho de Habermas. Rio de Janeiro: Tempo Brasileiro, 2002.

DURAND, G. $O$ imaginário: ensaio acerca das ciências e da filosofia da imagem. Rio de Janeiro: Difel, 1998.

FAZENDA, I. C. A. (Ed.). Dicionário em construção: interdisciplinaridade. São Paulo: Cortez, 2001.

GADAMER, H. Verdade e método: traços fundamentais de uma hermenêutica filosófica. Petrópolis: Vozes, 1997.

GADOTTI, M. Perspectivas atuais da educação. Porto Alegre: Artes Médicas, 2000. 
GHEDIN, E. Hermenêutica e pesquisa em educação: caminhos da investigação interpretativa. In: SEMINÁRIO INTERNACIONAL DE PESQUISA E ESTUDOS QUALITATIVOS, 2., 2004, Bauru. Anais... Bauru: Universidade do Sagrado Coração de Jesus e Sociedade de Estudos e Pesquisa Qualitativa, 2004. HÜBNER, K. Crítica da razão científica. Lisboa: Edições 70, 1986.

IRIBARRY, I. N. Aproximações sobre a transdisciplinaridade: algumas linhas históricas, fundamentos e princípios aplicados ao trabalho de equipe. Psicologia: reflexão e crítica, v. 16, n. 3, p. 483-490, 2003.

JANTSCH, E. Interdisciplinaridade: os sonhos e a realidade. Tempo Brasileiro, n. 121, p. 29-41, 1995.

JAPIASSU, H. Interdisciplinaridade e patologia do saber. Rio de Janeiro: Imago, 1976.

. Introdução ao pensamento epistemológico. Rio de Janeiro: F. Alves, 1992.

KUHN, T. S. Lógica da descoberta ou psicologia da pesquisa? In: LAKATOS, I.; MUSGRAVE, A. (Org.). A crítica e o desenvolvimento do conhecimento: quarto volume das atas do Colóquio Internacional sobre Filosofia da Ciência, realizado em Londres em 1965. São Paulo: Cultrix, 1979. p. 5-32.

LAKATOS, I.; MUSGRAVE, A. (Org.). A crítica e o desenvolvimento do conhecimento: quarto volume das atas do Colóquio Internacional sobre Filosofia da Ciência, realizado em Londres em 1965. São Paulo: Cultrix, 1979.

LUNA, F.; SALLES, A. L. F. Bioética: investigación, muerte, procreación y otros temas de ética aplicada. Buenos Aires: Sudamericana, 2000.

LUZ, M. T. Cultura contemporânea e medicinas alternativas: novos paradigmas em saúde no fim do Século XX. Physis: Rev. de Saúde Coletiva, v. 15, n. esp., p. 145-176, 2005.

MASTERMAN, M. A natureza de um paradigma. In: LAKATOS, I.; MUSGRAVE, A. (Orgs.). A crítica e o desenvolvimento do conhecimento: quarto volume das atas do Colóquio Internacional sobre Filosofia da Ciência, realizado em Londres em 1965. São Paulo: Cultrix, 1979. p. 72-108.

MINAYO, M. C. S. Interdisciplinaridade: uma questão que atravessa o saber, o poder e o mundo vivido. Medicina, Ribeirão Preto, v. 24, n. 2, p. 70-77, abr./jun., 1991. 
MORAES, M. C. O paradigma educacional emergente. Campinas: Papirus, 1997.

. Sistêmico. In: FAZENDA, I. C. A. (Ed.). Dicionário em construção: interdisciplinaridade. São Paulo: Cortez, 2001. p. 33-34.

MORIN, E. A cabeça bem-feita: repensar a reforma, reformar o pensamento. Rio de Janeiro: Bertand Brasil, 2000c.

. Ciência com consciência. Rio de Janeiro: Bertrand Brasil, 2000b.

. Introdução ao pensamento complexo. Lisboa: Instituto Piaget, 1995.

. O problema epistemológico da complexidade. Portugal: EuropaAmérica, [19-?].

. Saberes globais e saberes locais: o olhar transdisciplinar. Rio de Janeiro: Garamond, 2000a.

MORIN, E.; BAUDRILLARD, J.; MAFFESOLI, M. A decadência do futuro e a construção do presente. Florianópolis: UFSC, 1993.

NUNES, E. D. Interdisciplinaridade: conjugar saberes. Saúde Coletiva, v. 26, n. 62, p. 249-258, set./dez., 2002.

. A questão da interdisciplinaridade no estudo da saúde coletiva e o papel das ciências sociais. In: CANESQUI, A. M. (Org.). Dilemas e desafios das Ciências Sociais na Saúde Coletiva. São Paulo: Hucitec, 1995. p. 95-113.

OSUNA, I. B. Pensamento medico y etica clinica contemporanea. Instituto Superior de Ciencias Medicas de la Habana. Disponível em: <http:// www.bioeticaweb.com/Fundamentacion/pensamiento_medico_y_etica_clini.htm>. Acesso em:10 abr. 2003.

PICHON-RIVIÈRE, E. O processo grupal. São Paulo: Martins Fontes, 1998. Teoria do vínculo. São Paulo: Martins Fontes, 1986.

POPPER, K. R. A Ciência normal e seus perigos. In: LAKATOS, I.; MUSGRAVE, A. (Orgs.). A crítica e o desenvolvimento do conhecimento: quarto volume das atas do Colóquio Internacional sobre Filosofia da Ciência, realizado em Londres em 1965. São Paulo: Cultrix, 1979. p. 109-243.

RICOUER, P. Interpretação e ideologias. Rio de Janeiro: F. Alves, 1990. 
SANTOS, B. S. A crítica da razão indolente: contra o desperdício da experiência. São Paulo: Cortez, 2000.

TEIXEIRA, H. Holismo e medicina. Revista Virtual de Medicina. Disponível em: 〈http://www.medonline.com.br/med_ed/med8/holismo.htm〉. Acesso em: 2 abr. 2004.

TESSER, C. D.; LUZ, M. T. Uma introdução às contribuições da epistemologia contemporânea para a medicina. Ciência e Saúde Coletiva, v. 7, n. 2, p. 363-372, 2002.

TURATO, E. R. Tratado da metodologia da pesquisa clínico-qualitativa: construção teórico-epistemológica, discussão comparada e aplicação nas áreas de saúde e humanas. Petrópolis: Vozes, 2003

\section{NOTAS}

- Doutor em Ciências Biomédicas/Tocoginecologia (PPGTG) pela Faculdade de Ciências Médicas, UNICAMP, Campinas. Pesquisador do Laboratório de Pesquisa Clínico-Qualitativa (LPCQ). Endereço eletrônico: jrenato27@itelefonica.com.br.

- Orientador e docente no Programa de Pós-graduação em Tocoginecologia da Faculdade de Ciências Médicas da UNICAMP. Coordenador do Laboratório de Pesquisa Clínico-Qualitativa (LPCQ).Endereço eletrônico: erturato@uol.com.br. 


\section{Epistemological Discussion of Scientific Production for Post-} Graduation Programs in the Reproductive Health Area

The article presents preliminary research results, which understand that the consequences of the complex relation "production" (research)/"spreading" (education)/"use" (consumption) reproduce the dominant Newtonian-Cartesian thought in the academic context. The aim is to identify the level of epistemological discussion in theses of post-graduation programs in São Paulo universities (only theses from Unicamp have been analyzed so far), electing the production in Gynecology, Obstetrics and Mastology. The selection was based on chronology (the most updated), and randomized choice of methodological research type. Through hermeneutic analysis and saturation criteria, four categories were hypothetically searched - view of "person", "health", "ethics" and "science". The works have little or no concern with epistemological reflections. The structure of methodological aspects presents formal concerns in most cases, in a disciplinary and rationalist perspective, what impedes the concretization of academic actions that value the trans-disciplinary approach.

Key words: epistemology; ethics; reproductive medicine; education. 